\title{
The extra miles on preventing nephrogenic systemic fibrosis
}

\author{
A. Adhipatria P. Kartamihardja ${ }^{1,2}$, Yoshito Tsushima ${ }^{1,3}$ \\ ${ }^{1}$ Diagnostic Radiology and Nuclear Medicine Department, Gunma University Graduate School of Medicine, Japan; ${ }^{2}$ Department of Nuclear \\ Medicine and Molecular Imaging, Universitas Padjajaran, Indonesia; ${ }^{3}$ Gunma Initiative for Advance Research, Gunma University, Japan \\ Correspondence to: Prof. Yoshito Tsushima, MD, PhD. Department of Diagnostic Radiology and Nuclear Medicine, Gunma University, 3-39-22 \\ Showa, Maebashi, Gunma 371-8511, Japan. Email: yoshitotsushima@gunma-u.ac.jp.
}

Comment on: Attari H, Cao Y, Elmholdt TR, Zhao Y, Prince MR. A systematic review of 639 patients with biopsy-confirmed nephrogenic systemic fibrosis. Radiology 2019;292:376-86.

Submitted Sep 06, 2019. Accepted for publication Sep 13, 2019.

doi: 10.21037/qims.2019.09.17

View this article at: http://dx.doi.org/10.21037/qims.2019.09.17

Since the first discovery for magnetic resonance imaging (MRI) and its clinical application for medical diagnostics, Gadolinium (Gd)-based contrast agents (GBCAs) are possibly the most important feature to improve the diagnostic yield of MRI. Although chelation of Gd significantly improved the safety profile of GBCAs, it was discovered that GBCAs may still pose a threat being one of the lanthanides with high toxicity (1). The heightened issue in GBCA safety for clinical application is centralized in possible adverse effect of $\mathrm{Gd}$ retention in human tissues, clinical manifestations that may be caused by this retention and whether vulnerable population will be more at risk.

Decade before Gd retention was discovered, GBCAs application in clinical practice was linked with development of a rare yet lethal disease that is nephrogenic systemic fibrosis (NSF). This debilitating disease may affect multiple organs including muscles, lung, liver and skin as the most prominent organ affected (2). NSF was found exclusively in patients with chronic kidney disease with estimated glomerular filtration rate (eGFR) less than $30 \mathrm{~mL} / \mathrm{min} / 1.73 \mathrm{~m}^{2}$ or patients suffered from acute renal failure. In $2006(2,3)$, it was shown that linear-chelate GBCAs, particularly the extracellular nonionic gadodiamide, may trigger the development of NSF. Food and Drug Administration issued a warning about using linear-chelate GBCAs in renally impaired patients in June 2006 (4).

Latest NSF review by Attari and colleagues (5) included almost twice as many cases compared to the similar review in 2011 (6), emphasizing the incidence comparison before and after the regulation taken place. In conducting systematic review, bias elimination is one challenging obstacle to overcome. The confounding bias in the review is still high and difficult to avoid despite incorporating numerous cases. Even without Gd exposure, renal failure may lead to several physiological and morphological changes such as fibrosis, monocytes and/or macrophages infiltration and alter vasoactive substances (7). Patients with end-stage renal disease (ESRD) may suffer systemic complications affecting multiple organs including fibrosis and skin involvement, causing a high number of confounding bias in this review. Despite numerous cases of NSF were reported in patients with chronic kidney disease injected with linear-chelate GBCAs, Gd may not be the sole cause of NSF but may serve as aggravating factors for severe symptoms, especially in the skin (8). It is important for doctors and health care provider to convey this message to patients and public, that such symptoms are not exclusively caused by administration of GBCAs.

There are three NSF cases reported in patients with chronic kidney disease after exposure to macrocyclic-chelate GBCA, gadobutrol (Gadovist, Bayer AG) $(9,10)$. Two cases were only exposed to gadobutrol, while the other one was exposed to linear-chelate GBCA, gadodiamide (Omniscan, GE Healthcare) at 7 years prior to administration of gadobutrol. The symptoms from two patients were noted about a week after gadobutrol administration. One patient developed NSF at 16 months after gadobutrol administration. Despite the rarity of macrocyclic-chelate 
GBCA-induced NSF, we should be cautious not to diminish gadobutrol involvement in the case. We cannot put aside that macrocyclic-chelate GBCAs has significant lower market share over time compared to linear-chelate GBCAs, resulting in lower cumulative dose administered globally.

The peak incidence of NSF from this review was reported in patients at their fifties, which was at a similar age range with the similar review from 2011. Diminishing number of cases in the elderly population included in both review (>70 years old) despite being more at-risk category group is one of the key points in both systematic reviews. Although GBCAs elimination is essential, and that NSF was exclusively found in patients with severe kidneys problem, low filtration and elimination rate are not the only major factors that contribute to the development of NSF. On the other hand, as aging continues, there are several changes of both innate and acquired immunity that may lead to alteration in response to foreign materials, including Gd (11). The aging factors needs to be considered to explain lower incidence of NSF in elderly population ( $>61$ years old) despite a growing occurrence of reduced glomerular filtration rate in this population group. We strongly agree that the immune response of elderly population to GBCAs may be different from the younger adults thus reducing the risk of NSF development.

The authors suggested that screening of renal function is not needed for administration of Group II GBCAs (agents associated with few, if any, unconfounded cases of NSF). However, gadobenate dimeglumine and gadoxetate disodium are linear-chelate GBCAs included in group II GBCAs. Although gadoxetate disodium may be safer due to its half $\mathrm{Gd}$ dose and $50 \%$ elimination by the liver, it still poses a risk because its chelate type and Gd from this agent may also deposited in the tissue (12). The FDA approved both agents in 2003 and 2008; respectively, thus the estimated number of global administrations is much lower compared to gadodiamide or gadopentetate dimeglumine.

NSF is considered a long-term side effect of GBCAs administration that although it mostly occurs in days to months, it can take years before the symptoms occur. In an animal study, injection to both normal and renal failure mice model results in prolonged Gd retention (13), however there are no immediate sign and symptoms of NSF that were observed. One case of NSF was reported in a long-term hemodialysis patient who was exposed to three different linear-chelate GBCAs ten years prior to the NSF development (14). Gd may be deposited in the patients' tissue for a very long time without proper elimination and the immune response was triggered a decade after the last administration of the GBCAs. Therefore, we should consider screening of renal function is still necessary before group II GBCAs is used.

This systemic review showed that the regulation for GBCA use in clinical practice, including screening of renal function, careful review on population at risk (i.e., pregnant women, or patients with confounding disease), and whether the patients requires multiple dose, can almost eliminated new cases of NSF. Moreover, FDA published an updated medication guideline on GBCAs use in clinical practice (15). Systematically documented clinical findings will greatly improve future study to prevent negative outcomes from a medical procedure, including NSF. Emerging reports of Gd retention in the tissue, in addition to NSF cases from before the regulation put into effect raised a controversy in contrast enhanced MRI. Thus, contrast enhance MRI should be carefully decided after weighing the patient's risks, by choosing the safest GBCAs and to use as low dose as possible.

\section{Acknowledgments}

None.

\section{Footnote}

Conflicts of Interest: The authors have no conflicts of interest to declare.

\section{References}

1. Ariyani W, Iwasaki T, Miyazaki W, Khongorzul E, Nakajima T, Kameo S, Koyama H, Tsushima Y, Koibuchi N. Effects of gadolinium-based contrast agents on thyroid hormone receptor action and thyroid hormone-induced cerebellar purkinje cell morphogenesis. Front Endocrinol (Lausanne) 2016;7:115.

2. Mendoza FA, Artlett CM, Sandorfi N, Latinis K, PieraVelazquez S, Jimenez SA. Description of 12 cases of nephrogenic fibrosing dermopathy and review of the literature. Semin Arthritis Rheum 2006;35:238-49.

3. Grobner T. Gadolinium--a specific trigger for the development of nephrogenic fibrosing dermopathy and nephrogenic systemic fibrosis? Nephrol Dial Transplant 2006;21:1104-8.

4. FDA. Gadolinium-Based Contrast Agents for Magnetic Resonance Imaging (marketed as Magnevist, MultiHance, 
Omniscan, OptiMARK, ProHance). Information for Healthcare Professionals, 2007:1-5. Available online: https://www.ismrm.org/

5. Attari H, Cao Y, Elmholdt TR, et al. A Systematic Review of 639 Patients with Biopsy-confirmed Nephrogenic Systemic Fibrosis. Radiology 2019;292:376-86.

6. Zou Z, Zhang HL, Roditi GH, Leiner T, Kucharczyk W, Prince MR. Nephrogenic systemic fibrosis: Review of 370 biopsy-confirmed cases. JACC Cardiovasc Imaging 2011;4:1206-16.

7. Yu HT. Progression of Chronic Renal Failure. Arch Intern Med 2003;163:1417-29.

8. Wahba IM, Simpson EL, White K. Gadolinium Is Not the Only Trigger for Nephrogenic Systemic Fibrosis: Insights From Two Cases and Review of the Recent Literature. Am J Transplant 2007; 7:2425-32.

9. Elmholdt TR, Jørgensen B, Ramsing M, Pedersen M, Olesen AB. Two cases of nephrogenic systemic fibrosis after exposure to the macrocyclic compound gadobutrol. NDT Plus 2010;3:285-287.

10. Wollanka H, Weidenmaier W, Giersig C. NSF after

Cite this article as: Kartamihardja AAP, Tsushima Y. The extra miles on preventing nephrogenic systemic fibrosis. Quant Imaging Med Surg 2019;9(11):1911-1913. doi: 10.21037/ qims.2019.09.17
Gadovist exposure: A case report and hypothesis of NSF development. Nephrol Dial Transplant 2009;24:3882-4.

11. Accardi G, Caruso C. Immune-inflammatory responses in the elderly: an update. Immun Ageing 2018;15:11.

12. Kim SY, Maurer MH, Richter JK, Heverhagen JT, Boehm IB. Gadolinium depositions after the application of the hepatospecific gadolinium-based contrast agent gadoxetate disodium. Eur J Intern Med 2018;47:e9-e11.

13. Kartamihardja AA, Nakajima T, Kameo S, Koyama H, Tsushima Y. Impact of Impaired Renal Function on Gadolinium Retention After Administration of Gadolinium-Based Contrast Agents in a Mouse Model. Invest Radiol 2016;51:655-60.

14. Larson KN, Gagnon AL, Darling MD, Patterson JW, Cropley TG. Nephrogenic Systemic Fibrosis Manifesting a Decade After Exposure to Gadolinium. JAMA Dermatol 2015;151:1117-20.

15. Anon. Medication Guides. Available online: https:// www.accessdata.fda.gov/scripts/cder/daf/index. cfm? event=medguide.page 